\title{
'Kiki Salon Presents...': A Journey into Conceptual Brand and Product Development utilising Social Networking and New Media to Analyse Issues of Diversity, Authenticity and Collaborative Practices in Art and Design
}

\author{
Rob Burton \\ Principal Lecturer in Art and Design - Research. \\ School of Arts and Media \\ Teesside University \\ Middlesbrough \\ Tees Valley \\ TS1 3BA UK \\ 01642342594 \\ R.Burton@tees.ac.uk
}

\begin{abstract}
This paper investigates the nature of remote and virtual creative interaction; the issues, potential and questions arising in the uniting of a diverse group of people as a collaborative working team in the development of a range of digitally generated products and creative outputs. In the early $20^{\text {th }}$ century Zika Ascher established a textile concept that integrated the provenance of high craft with the creativity of the leading exponents of the art world. Using a unique approach to making Ascher commissioned artists to generate imagery that featured as an exceptional moderating collaboration between the dislocated fields of Art and design. Ascher collaborated with artists such as Matisse, Picasso, Alexandra Calder and Henry Moore inspiring and leading them to engage with new mediums and exciting forms of artistic expression. Bringing this ideology into the contemporary virtual landscape a conceptual brand was created in the winter of 2009 that explored the collaborative ground, non-located working processes, and the potential of developing a product with a virtual team to create a commercial product utilising digital technologies. A group of artists and creative makers from a wide range of backgrounds and diverse modes of creative expression, some established, others emerging or outsider artists, were invited to participate in the project though social networking. This paper reflects on the nature of collaborative working in the virtual worlds of social networking and new media. It problematizes methods of remote team building and working with virtual individuals. In the discussions arising from the case study issues of clarity, communication and isolation are considered and analysed within a clear theoretical context
\end{abstract}

Social Media. Collaborative Arts Practice. Digital Cultures. Social Networking.

\section{INTRODUCTION}

In 1936 Walter Benjamin (Benjamin 1999) published the seminal work 'The Work of Art in the Age of Mechanical Reproduction'. His discussion centred on issues of authenticity in a world fast becoming a web of technologies and a society, where, as the Situationists would later argue all is spectacle and the quality of life is hence impoverished (Debord 1992). Benjamin resolves this within the context of the early $20^{\text {th }}$ century by proposing that through the 'aura' of the artwork within the location of the site of production arises the sense of authenticity of the work. At the same time that Benjamin was publishing this authoritative work and questioning the appropriation and appreciation of art and the created image a Czech émigré Zika Ascher was in the process of setting up one of Europe's most influential textile print studios in London. In a narrative that can only be termed as mythologized Ascher, in 1946, went to Paris and using a telephone in the Cafe du Rond Point des Champs-Elysee, called Pablo Picasso, Henri Matisse and Andre Derain. Each one of them 
agreed to meet up with Ascher and what ensued can be seen as the start of one of the most audacious collaborations between the crafts of making; textiles and Art. In working closely with artists to capture on cloth the 'aura' of creativity of many of the most creative and highest profile artists of the modern era in the mid twentieth century Ascher developed a studio concept and a brand that would grow within his lifetime to be at the forefront of the art of design and textiles (Mendes, $V$ and Hinchcliffe, F 1987). Ascher showed a unique approach to the development of an identity for the fabrics he was producing. In working collaboratively with artists he created a two-way discourse that developed a clear identity for the collections of textile apparel designs and artefacts he was producing. Ascher was particular about the craft of making and the artists he worked with were mindful that their art was represented authentically within a textile medium.

It can be said that Ascher created a brand that can be easily recognized today and through the collaboration with artists developed a model of relevance to many of the activities of global brands today. An original Ascher scarf is supremely desirable and because of the unique collaborative and working practices with many of the significant artists of the twentieth century command a high price currently at auction and are desired by collectors globally. It is important to state that the images used were neither reproductions nor commercial patterns but were original artworks on cloth bringing together the skill of making with the creativity of artistic endeavour. The Ascher brand was established as having provenance through its relations with the arts and contemporary culture, which gave it a strong identity and authenticity with fashion and couture designers, who would then commission unique pieces from Ascher. This initial platform assisted the Ascher brand to work across commercial practices and levels of production from collaborating closely with many of the fashion world's greatest names at the couture level to printing relatively low cost utility fabrics for the high street.

The term 'brand' can be perceived as standing for a symbol or identity of a product that has good quality, reliability and a brand's image projects and sustains concepts of performance and reliability as a symbol of consistency. The brand was conceived as a marketing device to seduce consumers and we have come to a self-realisation of ourselves and our daily lives through the perception of the brands in the world around us. Branding is now immeasurable in social and cultural terms and the image of a product, service or institution is signified by the power of the brand and the visual image that symbolises it (Olins,W. 2003). It can be argued that by associating his products with the authenticity and cultural integrity of the most prominent artists and creative minds of the mid twentieth century modern world Ascher created by association a strong and powerful brand producing product that crossed disciplinary boundaries and commercial perspectives in a society that was comparatively separate and compartmentalised in comparison to the diversity and shifting diasporas of 21 st century communities.

The visual is essential to the way that we interpret the world and how society and cultural communicates values, concepts and ideologies. The strongest sense through which we interpret the world is through the seen and our perception about likes and dislikes and the choices made are informed by the signs encountered in everyday life. Boyce-Tillman suggests that in the early part of the $21^{\text {st }}$ century the West is attempting to heal the rift that has developed in rationalistic culture through a separation between two polarities of human personalities and characteristics. The first, type A, is rationalistic, objective whose traits are impersonal logic, thinking and thought whereas type B is subjective, involved, associative, emotional and feeling (Boyce-Tillman, J. 2005). There is a perceived correlation between these two archetypes and the philosophical and societal perspectives traceable from the Enlightenment to the early twentieth century. The Enlightenment promoted the logical, reason above all else and the rational establishment. It can also be considered by many theorists to be a one sided patriarchal perspective. Alternatively the type $b$ personality type responses to the contemporary and postmodern give rise to shifting perspectives and symbolised associations where the dominant codes have shifted from the textual and authoritative to the subjective and associated. We can align the type A characteristic as that of the modern era with a predominance of the textual and meaning being interpreted through language and the word. It can be argued that the contemporary dominant culture relates to the type $B$ in whom the sense of identity and association gained through the visual, the image and the sign is that of the world of the computer screen, television and the broadening range of telematic technologies. In the visual image messages are not fixed but fluid, moving and plural. Here lies our modern concept of the brand as the image of identity and sensuality within a visual language. It is the site of the story and storytelling; an image which is interpreted in many different ways and builds through associated concepts, mythologizing shifting ontology creates and projects colourful ideas, memories, personal narratives and associated imaginary identities over and over again. 
The telematic virtual worlds and online environments create an ever-diverse interplay of shifting realities in which to interact and appropriate through differing perspectives. The flow of movements is a shifting sand of information and the subjective form of the visual makes it very hard to define the authentic from the mythologized. The product becomes a separated subject that may be as imaginary as the textual narrative that builds its identity and desirability. Etienne Ozeki is a brand of jeans that ultilised storytelling in their online presence to create mystery and desirability around their products through the narrative and the associated imagery. The early websites told the story of Etienne, born to a French mother and a Japanese father, who cultivated global links as an international traveller around the world from an early age. Following a high profile academic career studying philosophy and the sciences he had amassed a substantial fortune by the age of 24 . His parents died tragically soon after this and he left to spend time in contemplation and working with nature on a remote island in the south pacific. The story goes on to tell how Etienne developed sustainable approaches to living and ecological inventions, which he sold to a Californian company. $\mathrm{He}$ then travelled meeting his life partner, again an exotic and mysterious personality from Cambodia and having several other Voltaire-esque adventures before releasing his first denim jeans collection available at stores in the UK and online in the year 2000 (http://www.etienneozeki.com/eo/history.htm). The narrative here creates an imaginary fiction around the life of the mythological founder of the products and supposes an assumed authenticity and provenance that is unreal. The myth though connects through the virtual environment the true site of shifting narratives and unsafe perspectives to speak directly to potential clients who will literally buy into the imagination of the brand. A world has been created that the perceived target market will immediately associate with through social norms and practices. The product, through its marketing strategies and especially through its virtual marketing presence, speaks directly through the imaginary narrative of Etienne, his emotive journey through success to loss and self-discovery connecting with the target audience through sympathetic association and shared dreams, experiences and lifestyles. Etienne reflects the contemporary soap opera in that events in his life could be events in our lives that we can relate to although it is so overplayed that no one life can be so involved with so many twists and turns. We can all connect with a part of Etienne's life and so affirm a sense of self through an affiliation with the brand.

\section{2. 'KIKI SALON PRESENTS...'}

\subsection{The Concept.}

The beginning of the $20^{\text {th }}$ century brought about an integrating and a merging of the boundaries between disciplines within the arts and culture and new thresholds appeared within which makers perceived themselves as within or outside (Hyde, L. 2008). Where previously there was a separation in both ideals and ideas between the fine, the applied and the commercial arts the boundaries have become blurred with a cross fertilisation of working practises, contexts of making and perceived audiences. Many groups of creative practitioners are working on new narratives across interdisciplinary perspectives with a breaking down of the social constructs and the perceived norms. Relationships are considered to be in a state of flux and the direction of movement being part of the flow of culture rather than the static sharp classifications such as male versus female, straight versus gay, white versus black, and imperial versus colonial. The apparent ontology is plural and relative, and dependent on who the interested parties are and what their particular interest are. In this cultural climate the concept of the virtual space of work is being perceived as the way forward as a way of connecting through facilitators that weave relations and lead practitioners working within global cultural economies. It was in this conceptual space that the project ' Miss Kiki Salon Present...' was founded. Kate Burton, the founder of the project, with a long background within branding design working with many of the leading global brand agencies, perceived the idea of an imagined protagonist. Her perception was that the field of design and branding had become formalised and stale and perceived itself as founded within commercial practices dislocating itself from the arts and the culture economies that it, necessarily, is a part of and its practices arise from. She perceived the art of creating a 'brand' of like-minded people gathered together to pool ideas, creativity and skills towards a common goal creating a visual and visible identity through and across media and communication technologies. Making a clear reference to the past the idea re-envisioned the French literary and philosophical movement of Salons of the 17th and 18th centuries. The 'brand' in the form of a salon would exist, in this way, as a virtual pool of talent that worked together on a project-by-project basis sharing the work, inspiring and nurturing each other's creativity and skills. A practitioner whose expertise was in technical making would facilitate the realisation of the ideas of creative individuals, artistic practitioners and visionaries bringing to life the imagination of others. A group of people would work together as a collaborative group nurturing the skills and attributes of another to create an output greater than the sum of its parts. It was considered 
important that all participants were involved in the process and that the invited participants were from a wide range of disciplines and walks of life. It was important to create diversity and inclusivity in developing a 'brand' that could respond to fluid outcomes and an exciting range of potential opportunities which might include traditional exhibitions, ranges of products and a whole spectrum of events. What was perceived as key to the methodology and the strategies employed was that from fluid and virtual interactions orchestrated by the director as protagonist real outcomes and objective outputs would result that would bring benefit to all the participants. Essentially a visionary idea that sat outside the conventional frameworks of the industrial and cultural traditions was intended to inspire those dislocated and alienated makers into a unique association uniting creativity, craft and making within a commercial focus. The project commenced with a refining of the concept and, taking inspirational references from Zika Ascher and his cross disciplinary activities of the 1930's and 1940's, a project evolved that would in integrate the disciplines of art practice and fashion making uniting the potential for a wide range of visual artists working in a wide range of media and different backgrounds to identify and appropriate the key aims of the concept. The proposal was to create a range of fashion accessories to be promoted, marketed and produced as a high quality desirable product bringing the work of unknown artists into a new sphere through an audacious interventionist strategy that clearly placed itself within the threshold between fashion and fine art practice.

\subsection{The Call for Artists.}

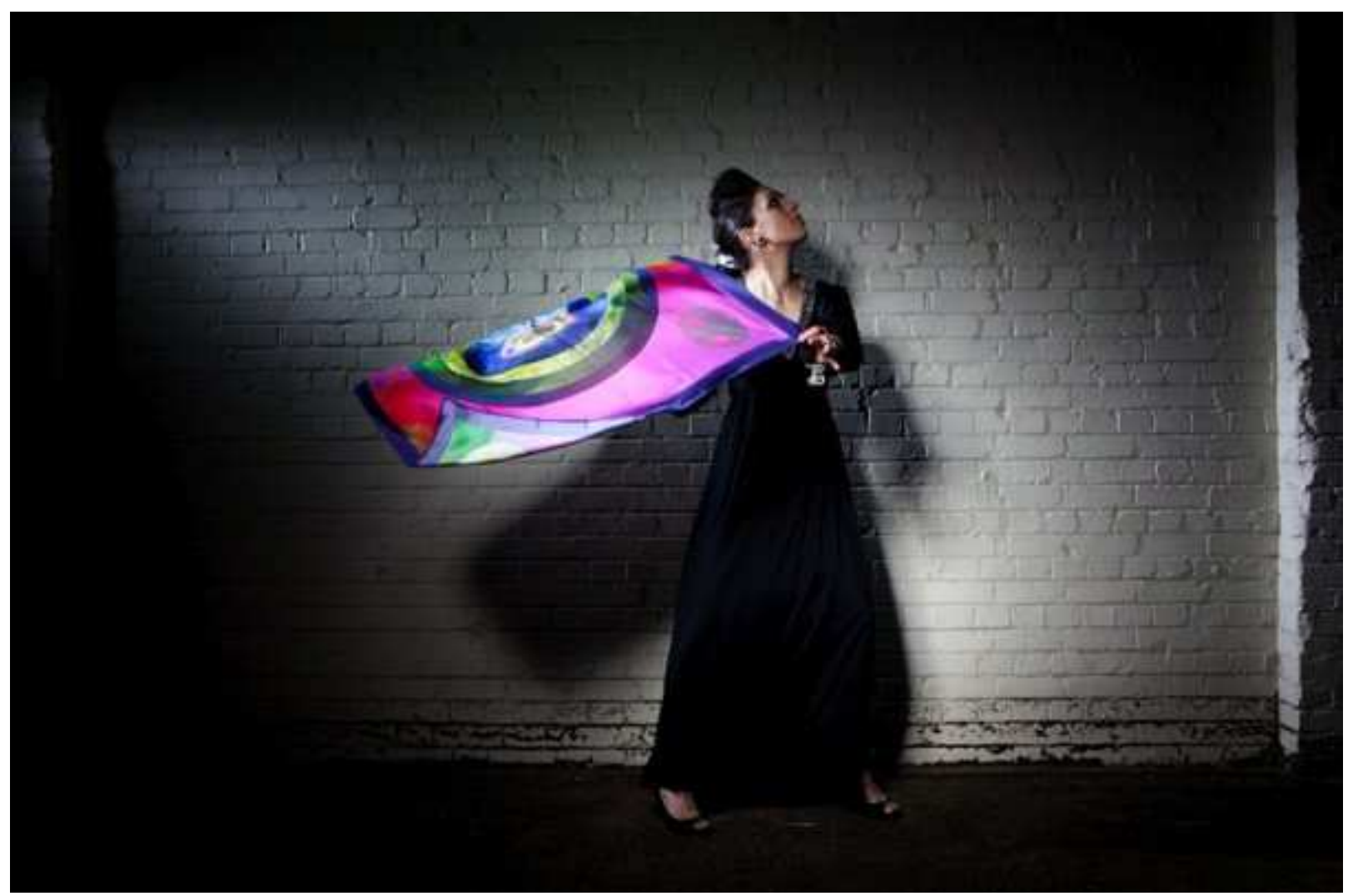

Figure 1: Still from Performance - LookbookPerformance at 'Kiki Salon Presents...' Exhibition and Event

\section{Performer: Stav B. Photographer Georgie Clark Copyright: Embodied.creative}

Following the development of the strategy artists and participants were approached through online social media. The project 'Kiki Salon Presents ..." grew rapidly with much interest and individuals and groups became connected by the vibrant and dynamic web of influence through interaction and engagement with digital cultures. By connecting initially with known associates, performers, artists and many diverse creative practitioners a web of interest soon built up with its own energy and began to, rather than reach out to people, to draw into its collective network people who saw an 
interest and investment in the project. One of the first people to become a participant artist in the concept was from a performance background but whose current practice was visual art works in a 'lowbrow' style. Her work was very popular on Facebook and she was very active promoting her work and networking to publicise her portfolio on the Internet with profiles in online galleries and a high level of promotional activity on Facebook. It was thought that as most of the collaborators that would be recruited to the project were from different backgrounds with varying perceptions of outcomes that everyone should, as much as possible, be 'interviewed' face to face as the project would be described and information given as to the expectations of the project. This was essential as each member of the team working towards each different outcome would be from a diverse background and would be guided to work on a project that did not necessarily fall in their normal field of practice. For the former participant one of the challenges was that all her artworks were computer generated through much iteration to a very high degree of finished and she had no conception of how this work might be re-envisioned into objective forms or experience of conventional media and aesthetic practices. It was essential to guide participants through the technical aspects of making to transfer the high quality of the images from their original states whether sculpture, painting or virtual imagery to the two-dimensional digitally printed image on a silk square. Another set of contributors had been active for some while developing their personal style of decorative artworks and had a growing reputation through commissions produced for a UK based boutique hotel group. The concept was perceived by them as a way of gaining a wider following for their own work, connecting with a broader range of outputs for their designs and networking to improve their own brand and commercial awareness. Again their work was mostly generated through electronic media and in other instances existed as digital print for decorative products. Working with the concept improved their own brand and developed the perception and quality of their output to higher level. The selection of participants was limited to six artists with another six participants from related industries including branding, performance and pr as this was considered a critical mass to produce a strong collection of high quality prototype products. Many of the artists were coming to the world of visual arts, the cultural community and the gallery system of formal art practice from an outside point of view. An international artist and arts professional with over twenty years experience curated the work but the submission and selection procedure was nonstandard as selected works and participants were approached and invited as and when, either, the work incidentally arose over social media or through the accidental meeting. It was therefore imperative that issues regarding external perceptions of commercial practices, sites of audience and production of the work and issues of negotiation of ownership were agreed from the outset. This became a distinct challenge with most of the work being developed was in a virtual format to begin with and had no objective presence with five of the six artists being digitally based and only becoming introduced to commercial practices through the project. The participants in the project were invited to take ownership of the project through interaction on Facebook, email lists and Skype sharing ideas about the development of the artworks and negotiating the process through regularly electronic discourse. This was particularly important for one participant who was a resident of Australia and had asked to be part of the project by joining the going enthusiastic response through Facebook. She was one of the most experienced of the participants and had a large network of arts professionals in London and had herself begun her career as an international photographer in London and had much experience of the commercial gallery system and knowledge of its practices.

\subsection{The Exhibition and the Event.}

An energy was built up through vital and responsive communication on Facebook and an exhibition was planned to promote the work of the artists as individuals and cooperation of the collected makers under the banner of the brand "Miss Kiki Salon Presents...". The work featured showed their unique identity as creative individuals and the product of the collaborative partnerships in the silk art panels (Fig 1). The exhibition took place with a high profile opening event listed and featured as part of the London Fashion Week schedule spring 2010. In a narrative that starts with a virtual brand that unites in collaborative practice diverse artists it was essential that all the stakeholders had a real presence within the exhibition that gave them value as individuals. What must also be said is that in keeping with the nature of the project the objective setting of the exhibition was within the gallery space in central London owned and run by a digital branding and design agency. This was the second exhibition to be held at Reading Room in Frith Street Soho which has since gone on to establish itself as a major gallery space within central London.

One of the central themes arising from the analysis of this project is the nature of creative work that exists on the threshold of the actual and the non located practice of the "new worlds of cyberspace" (Gunkel,D.J and Gunkel,A.H 1997). The brand itself was set as a protagonist intervention that brought together the work of diverse makers selected through cultural contexts appropriated on social networks within a gallery space run by an 
agency specialising in the ephemeral imagery of new media and digital technologies. The space had been designated by the agency as an exhibition space in response to issues regarding cultural and creative provenance of an agency whose work only existed in a digital environment. In order to buy into a cultural economy and by association engender their commercial practice with creativity and integrity it was considered imperative to have an actual located space, which expresses cultural capitol.

\section{3. "IT'S ALL SMOKE AND MIRRORS" PUBLIC AND PRIVATE SPACES - THE VIRTUAL LANDSCAPE AND THE ROLES THAT ARE ASSUMED WITHIN IT.}

The Etienne Ozeki jeans brand, as discussed previously, presents a narrative in which the reader becomes involved and associated with the characteristics and personality of Etienne; his loves, his life, adventures, explorations and dreams. The story draws the reader in, bringing the self into the world of the brand's founder and by association the product. It was the intention in the creation of the brand world and brand story of Kiki Salon for the character to be presented as a London socialite frequenting the galleries, salons and cultural communities and being cognoscenti with London's high society so as to engender a sense of the mysterious and the alluring be associated with the product itself. The images that were presented in web pages and internet presence signified a provenance and tradition that denoted quality and, within this, there was certainly a large element of truth with the brand founder being associated with many of the leading creative people, artists and prominent design agencies in London. The relationship between the presented narratives and what might be perceived as real comes into question when the personal relations between those involved through social networks are founded on each individual's self perpetuated ontology that is shifting and relies on a virtual identity and fragmented experiences of life perceived through digital media. The growth in social networking through sites such as Facebook, Myspace and others has broken down geographical boundaries and many of the societal separations that previously existed but it can also be suggested that that it has created greater separations and isolates the individual so that often the thoughts expressed are dismembered voices trying to connect (Locke, J. 1998). It must be considered that social networking can be a key tool for developing commercial and business practises but must also be considered with respect and attention to contexts of prior knowledge; traditional social constructs and established cultural practices. Relationships can be enhanced and deepened and a growing web of influence extended but only from a background and basis in the sphere of knowledge to begin with. Cooper, Green, Murtagh and Harper define contemporary virtual society as a mobile society whose perception of private spaces and public spheres has been redefined through new media and the shifting forms and associations of contemporary life (Cooper,G. Green,N. Murtagh,G.M and Harper,R). What was clearly defined as the public face and the private place previously were fixed and secure but traditional conceptions of community and the 'stranger' or Other have changed and often perceptions of self are being re-visioned through the effects of consumption and the building of a public identity using new media with style connotations and a branding of the self. Social networking as a place of community is responded to and exploited by its users in many different ways. The connecting with 'friends' creates a competitive edge and the potential to be seen as a popularity contest. Many people who perceive themselves as being part of a tribe or interest group use it to broaden their interests within the group. It can often be perceived as a home for the separated, alienated and alone in which they can feel part of a community or group. Often now it is being used as place for self promotion, narcissism and self exposure with an identity which is created to market either the individual as a personality, the activities of the individual, the business of the individual or the commercial activities of the group (Scott,D.M 2010). The exploitation of social media by the individual has changed radically in sophistication and range since Gleick referred to an individuals interface with the screen in 1996 as a hall of mirrors that he decribes as "circular and incestuous". His argument is very valid within the new arena of social media. The world of social media is a forceful form of marketing for the individual or the interest group where previously through traditional means advertising and publishing could be easily identified. The easy access to social media means that anyone can now command public attention and often not by the means we would normally accept (Gleick,J. 2002). Facebook friends and 'likes' bring us into an encounter with illusion and persuasion. Gere states that "there is a strong incitement to narcissism in much of what the new media are offering" and he goes onto suggest that this might be the reality of Andy Warhol's famous prediction of the coming celebrity culture (Gere,C. 2008). The promoting, recruiting and curating of an activity as a collaborative and participatory venture through the medium of Facebook brings one face to face with assumed personas and illusory. In bringing people together mainly within a virtual forum with communication and negotiation being within a public sphere under the umbrella of a created narrative the biggest impact and negative emotion 
is that of trust. Locke states that "estrangement creates suspicion and when people don't know each other it's hard for them to trust each other" (Locke, L. 1998) and this is very much the case in the forming of virtual relations towards a mutual goal such as a product development or a commercial activity. The social network as a space for public and press relations can be a vital force for pushing forward a positive identity and influencing brand awareness. Virtual space, though is an open forum where messages can be free to many interpretations and a public forum is open to interpretations that can be endemic. Confused messages and lack of clarity in any public forum can challenge quantifiable goals and the public face of the brand, which in using social networking, blogging and social media can throw up conflicting narratives. In a world of floating stories much of what is perceived through new media lacks substance and is merely 'smoke and mirrors'.

\section{ON REFLECTION: AUTHENTICITY AND OWNERSHIP OF THE REAL AND THE VIRTUAL, THE INTEGRATION OF DISCIPLINES AND COLLABORATIVE WORKING AND PRACTICES.}

In the evaluation of the creation of a virtual brand to develop product through a collaborative team curated through social networking, blogging and new media much of the creative work was digital and had no physical presence of itself. This brought into debate considerations of ownership once the image had become a commercial product and the value judgements of the creative act as opposed to those of creative direction and creative production. Issues of authenticity were approached with collaborating participants through joint working practices where both the digital artists and the technical production team established high quality and reproduction values and worked strategically in order to achieve a quality and gain esteem through the product. In the open forum of the internet and digital culture where many practitioners from a wide variety of social and economic backgrounds are motivated and active to be a part of the creative economy many artists struggle to find a way to communicate their activity and its meaning (http://www.emergence.cc/futureofart/). In the evolution of the 'Kiki Salon Presents...' project artworks were translated through a cross disciplinary environment that gained a greater circulation for the digital art form in a collection that was greater than the sum of its parts. The outcomes could be held, manipulated, were tactile and the virtual became embodied. Artists making projects that are virtual rather than objects often find it harder to establish themselves within the traditional arenas and mainstream commercial art worlds. Through their experiences in collaborative and cross-disciplinary working practices many of the participants have carried on working in this way after the completion of the project.

Through the practices of the project, the process and the methodologies the 'Kiki Salon Presents...' concept can be can be seen as a networked process. From conception to conclusion it can be seen as an example of networked art. Deriving from its initial networking stage it involved a process and developed a narrative about relations between people and people, and individuals and the group, the dynamic of social relations and interaction through social networking, email and the media (Kimbell,L 2006). In many respects the products and the nature of the outcomes with respect to commercialisation were secondary to the collaborative practices and storytelling that brought to the surface the questions of constantly shifting individual and group realities and fictions. In response to Roy Ascott's question 'Is There Love in the Telematic Embrace' it can be seen that universal access to the technologies of computerised media and telematic systems brings new players into the creative arena with the ability to engage with expression in new forms, to engage socially through social media, to publish and publicise work, to collaborate and come together to facilitate knowledge partnership and knowledge exchange (Ascott,R. 245:2007). An embrace can hold together and possesses the potential for innovative practices, new concepts and forms of collaboration. In the virtual time and space of the telematic embrace is a whole world of psychologies that are played out every day within a 'vehicle of consciousness' that creates a flow of relations between self and other, the separated and the community, the included and the excluded, connected and the alienated and all the human emotions of the egoic mind that are the part of normal human relations that are resolved everyday through the embodied communication of the senses; suspicion, jealousy, hate, greed, love, desire and hope. Each journey we commence is the beginning of a story. It is planned and as we move through it new elements and avenues are revealed to the participants. As a group of individual people we may join together as fellow travellers for a while; some for the whole journey others for only a few miles, some may voice their decent and decide on a different path. In the journey of the 'Kiki Salon Presents...' brand concept of fluidity through media; the subjective and telematic, the creative and the objective, experiential and consequential, the fluid productivity can be evidence in the new independence individually experienced by the collaborative practitioners and the inspirational and dynamic potential it has instilled in them to nurture their creativity, their social practices and their networks of influence. 


\section{REFERENCES}

Ascott,R. (2007) Telematic Embrace visionary theories of art, Technology and Consciousness. London: University of California Press Ltd.

Benjamin,W. (1999) Illuminations. Pimlico; New edition.

Boyce-Tillman, J. (2005) Subjugated Ways of Knowing. In Clarke, C. (ed.) Ways of Knowing: Science and Mysticism Today. Imprint Academic: Exeter.

Cooper,G. Green,N. Murtagh,G.M and Harper,R (2002) Mobile Society? Technology, Distance, and Presence in Woolgar,S. (ed.) Vitual Society? Technology, Cyberbole, Reality Oxford: Oxford University Press.

Debord, G. (1992) The Society of the Spectacle. London; Rebel Press; New edition.

Gere, C. (2008) Digital Culture. Reaktion Books Ltd: London.

Gleick, J. (2002) What Just Happened Abacus: UK.

Gunkel, D.J. and Gunkel,A.H. (1997) Virtual geographies: The new worlds of cyberspace. Critical Studies in Mass Communication, Vol. 14 Issue: 2.
Hyde, L. (2008) Trickster Makes This World: How Disruptive Imagination Creates Culture. Cannongate Books Ltd: Edinburgh.

Kimbell,L. (2006) If networked art is the answer what is the question. In Corby,T. Network Art Practices and Positions. Routledge: Oxon..

Locke, L ,J. (1998) 'Why we don't talk to each other anymore': The De-voicing of Society. Touchstone: . New York.

Mendes, V and Hinchcliffe, F. (1987) Ascher: Fabric, Art, Fashion (Victoria and Albert Museum); $\mathrm{V}$ and $\mathrm{A}$ publications: London.

Olins,W. (2003) On Brand: Thames and Hudson Ltd: London.

Scott,D,M. (2010) The New Rules of Marketing and PR: How to Use Social Media, Blogs, News Releases, Online Video, and Viral Marketing to Reach Buyers Directly. John Wiley \& Sons: UK.

Voltaire. 2007 Candide London:Penguin Classics; New edition.

EtienneOzeki

http://www.etienneozeki.com/eo/history.htm March 2011).

(8th

Future of Art http://www.emergence.cc/futureofart/ (accessed 10 ${ }^{\text {th }}$ March 2011). 